\title{
Multi-object approach and its application to adaptive water management under climate change
}

\author{
HONG Si ${ }^{1,3},{ }^{*}$ XIA Jun ${ }^{2}$, CHEN Junxu ${ }^{4}$, WAN Long ${ }^{1,3}$, NING Like ${ }^{1,3}$, SHI Wei ${ }^{2}$ \\ 1. Key Laboratory of Water Cycle and Related Land Surface Processes, Institute of Geographic Sciences and \\ Natural Resources Research, CAS, Beijing 100101, China; \\ 2. State Key Laboratory of Water Resources and Hydropower Engineering Science, Wuhan University, Wuhan \\ 430072, China; \\ 3. University of Chinese Academy of Sciences, Beijing 100049, China; \\ 4. School of Resource, Environment and Earth Science, Yunnan University, Kunming 650091, China
}

\begin{abstract}
This paper addresses issues on adaptive water management under the impact of climate change. Based on a set of comprehensive indicators of water system, a decision making approach of multi-objects is developed and applied to quantify water adaptive management for the demands of water sustainable use, water environmental protection and eco-water requirement under the climate change. For this study in China, two key indicators are proposed, namely (1) the water resources vulnerability (V) that was represented by integrated sensitivity $(\mathrm{S})$ and resilience $(\mathrm{C})$ of climate change impact on water resources, and (2) the sustainability of socio-economy and water environment, marked by $\mathrm{DD}$, that is integrated scaler of socio-economic development (EG) based on the amount of GDP and the water environment and relative eco-system quality (LI). To find a reasonable solution for adaptive water management, a multi-objective decision making model of adaptive water management is further developed and the multi-objective model was transformed into an integrated single optimization model through developing an integrated measure function, called as VDD=DD/V. This approach has been applied to adaptive water resources planning and management for case study of China with new policy, called as the strict management of water resources based on three red line controls, i.e., the control of total water use by the total water resources allocation, the control of lower water use efficiency by the water demand management and the control of the total waste water load by water quality management in the Eastern China Monsoon Region that covers major eight big river basins including Yangtze River, Yellow River, Haihe River and Huaihe River. It is shown that the synthetic representation of water resource vulnerability and socio-economic sustainability by the integrated objective function (VDD) and integrated decision making model are workable and practicable. Adaptive management effect of the criterion compliance rate and water use efficiency are more appreciable through new water policy of the three red line controls, which can reduce $21.3 \%$ of the water resources vulnerability $(\mathrm{V})$ and increase $18.4 \%$ of the sustainability of socioeconomy and water environment (DD) for the unfavorable scenario of climate change in
\end{abstract}

Received: 2016-01-27 Accepted: 2016-04-11

Foundation: Major National Scientific Research Projects, No.2012CB956204; National Basic Research Program of China, No.2015CB452701, No.2010CB428406; National Natural Science Foundation of China, No.51279140

Author: Hong Si, PhD, specialized in climate change and water resources. E-mail: honora_vicki@163.com

*Corresponding author: Xia Jun, Professor, E-mail: xiaj@igsnrr.ac.cn 
2030.

Keywords: adaptive water management; climate change; multi-object; vulnerability; sustainability; VDD

\section{Introduction}

The impact of climate change on water resource and the adaptive water management become a very important issue in the world and also in China (Bates et al., 2008; Xia et al., 2011; Akamani et al., 2011). There is much relative research and different definitions on adaptive water management at home and abroad (Govert, 1995; Sophocleous, 2000; Liao et al., 2004; Pahl-Wostl et al., 2005; Moglia et al., 2011). Based on relative research and analysis, the adaptive water management can be defined as a structured, iterative process of robust decision making in the face of uncertainty due to climate change, with an aim at reducing risk over time via system monitoring and time-variant planning and management. In this way, decision making simultaneously meets one or more resource management objectives and, either passively or actively, accrues information needed to improve future management. Adaptive management is a tool which should be used not only to change a system, but also to learn about the system (Holling, 1978). Adaptive management can improve long-run management outcomes based on a learning process. The challenge in using the adaptive management approach lies in finding the correct balance between gaining knowledge to improve management in the future and achieving the best short-term outcome based on current knowledge (Allan et al., 2008). And according to those this paper gives its own definition of adaptive water management as the generation of the implementation of water resources planning and water management strategies, including adverse effects caused by climate changes on water resources. It adopts a systematic procedure for learning and adjusting to improve the policy and practice of water resource management. It is aimed at enhancing the adaptive capacity and management policy of a water system to reduce water resource vulnerability caused by environmental change and to realize socio-economic sustainable development and sustainable utilization of water resources.

Since the 1990s, many related studies of water resource adaptive management to cope with climate change have been carried out at home and abroad (Aronson et al., 1992; Govert, 1995; Sophocleous, 2000; Liao et al., 2004; Gregory et al., 2006; Tong et al., 2006; Pahl-Wostl et al., 2008; Xia et al., 2008; Jin et al., 2010; Liu, 2010; Moglia et al., 2011), which mainly focused on the adaptive framework and countermeasures. For example, Govert D. Geldof considered the overall process of water resource integration management as a complex adaptive system to seek an equilibrium strategy adapted for constant change and to perform early water resource adaptive management (Govert, 1995). Pahl-Wostl proposed that adaptive management has a general iterative process, including setting management goals; establishing management policy; implementing, monitoring and evaluating policy; and evaluating national policy. After national policy evaluation, it will perform feedback on the original objectives and policies in the early stage loop iteration (Pahl-Wostl, 2008). In order to use water resource efficiently, Gregory $\mathrm{R}$ et al. established a framework based on strategy analysis and applied adaptive management to the environmental policy of water resource utilization in British Columbia (Gregory et al., 2006). Tong Jinping et al. 
ventured the architecture of water resources adaptive management for a river basin (Tong et al., 2006). Jin Shuai et al. analyzed defects of complexity, nondeterminacy and the current mode of management of water resources in a river basin. It proposed policy suggestions regarding five aspects, namely management environment, management system, decision-making mechanism, management, and scientific research function (Jin et al., 2010). Liu Fang proposed an organization structure related to adaptive water management in Shandong Province (Liu, 2010). Xia Jun proposed an evaluation tool for impacts of climate change (Xia et al., 2008).

The critical concept of the effect of climate change on water resources includes vulnerability, resilience, adaptation and comprehensive risk. Based on the latest research results of SREX, IPCC AR5 expanded the evaluation framework of climate change risks, and they emphasized the interactive connection between exposure risk, vulnerability and adaptation that resulted from disasters and socio-economic development since 2012. The relationship is as shown in Figure 1 (IPCC, 2013). Based on the study of theories and methods related to water resource vulnerability, it focused on exploration of adaptive water management. It quantitatively studied the effects of climate change on water resources.

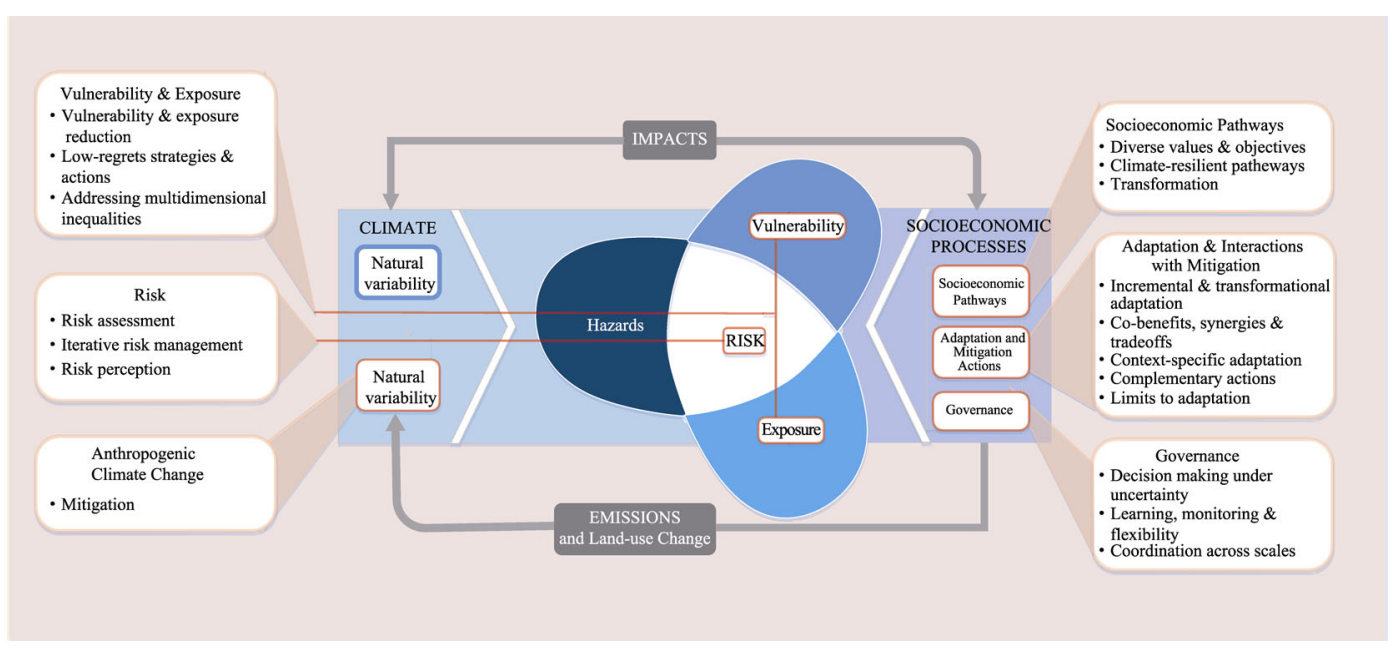

Figure 1 Framework diagram of risks associated with the interaction of hazard, exposure and vulnerability related to climate

(Note: The figure is originated from IPCC AR5, 2013.)

Research at home and abroad has made some recent progress now. Adaptive water management lacks an interactive system linking evaluation and adaptation of water resource vulnerability, which results in separate study of the vulnerability and adaptability of water resources. It lacks a connection and can hardly reduce the vulnerability of a water resource through adaptive management. Consequently, this paper attempts to establish a connection between adaptation and vulnerability, based on water resource vulnerability evaluation, to explore the multi-objective optimization problems based on the nature of adaptive management. It focuses on studies of conversion of multi-objects to single-objects to make adaptation countermeasures feasible. 


\section{Framework of adaptive water management based on a decision making approach of multi-objects}

Nowadays water resources system issues include water supply and water demands problem, water pollution and eco-water demands problem. So adaptive water management is a complex regulation system responding to climate change, involving multi-scales, processes (drainage basin hydrological processes, regional land surface processes, atmospheric circulation processes), interactions and control targets associated with natural and socio-economic systems. To address climate changes for sustainable utilization and management of Chinese water resources, it involves the effect of climate change on changes in water resource availability, changes in water consumption associated with industry, agriculture and environmental ecological use, as well as links to the balance between supply and demand for water resources and sustainable utilization of water resource problems. It is further related to support for socio- economic sustainable development of water resources security. Consequently, the model needs to consider objective criteria for combating climate change. It is necessary to establish a multi-objective model and solving method to establish water resource adaptive management practices specific to climate change scenarios.

\subsection{Comprehensive indicators of water system}

Climate change has caused many types of influences and consequences on water resources: destruction of the balance between supply and demand, unsustainable socio-economic development, and deterioration of the eco-environment are particularly significant. This study proposed two basic principles requiring adaptive water management related to quantitative research under the influence of climate change:

1) Reducing water resources vulnerability (V)

Water resource vulnerability refers to the degree of impacts of climate change on water resources (supply-demand relationship and configuration). It is expected that extreme weather events will become more frequent in the future. The pattern of southern floods and northern droughts will be further increased. In addition, the shortage of water resources will continue across the country, aggravating the water resources vulnerability. Consequently, adaptive water management requires the reduction of adverse effects on regional water resource vulnerability.

From the report of the IPCC, disaster risk represents the intersection of weather, climate events, and system vulnerability. Clearly, the water resource vulnerability should not only consider the sensitivity of the climate, but also the resistance of the system to socio-economic pressure. The adaptability is related to socio-economic scale, water resource endowment and exposure. Thus, the paper will extend the treatment of the core water resources vulnerability to respond to climate change, population carrying capacity and socio-economy under adverse conditions. The formula is (Xia et al., 2012; Chen, 2014):

$$
V I=f(S, C, E, R I)
$$

where $V I$ is the vulnerability index, $S$ is sensibility, $C$ is resilience, $E$ is exposure, and $R I$ is the risk index.

According to the IPCC report, Xia Jun et al. proposed that vulnerability should be evaluated based on the effect of sensitivity and adaptability on water resources in response to 
climatic variation (Xia et al., 2012; Chen, 2014):

$$
V=\frac{S(t)}{C(t)}
$$

where $S(t)$ is the sensitivity function, $C(t)$ is the resilience function or recoverable function, and $t$ refers to evaluation time.

When performing the evaluation of multi-attributes of the system, the formula can be synthesized as the vulnerability (Chen et al., 2014):

$$
V=\prod_{i=1}^{n}\left(\left(\frac{S(t)_{i}}{C(t)_{i}}\right)^{\left(\beta_{1}\right)_{i}}\left(E(t)_{i}\right)^{\left(\beta_{2}\right)_{i}}\left(R I(t)_{i}\right)^{\left(\beta_{3}\right)_{i}}\right)^{\theta_{i}}
$$

where $V$ refers to comprehensive vulnerability, $S(t)_{i}$ refers to the sensibility of the water resource system on the $i$ th paper evaluation, $C(t)_{i}$ refers to the resilience of the water resource system on the $i$ th evaluation, $E(t)_{i}$ refers to the exposure of the water resource system on the $i$ th evaluation, $R I(t) i$ refers to the risk index of the water resource on the $i$ th evaluation, and $\theta_{i}$ refers to the corresponding scale factor of the $i$ th evaluation.

2) Enhancing the sustainability of socio-economy and water environment (DD)

First of all, sustainable development requires that the life-support system on the earth (such as air, water and soil) is not destroyed; namely, human well-being should be ensured at least under the conditions for survival within the maximum carrying capacity limits. Simultaneously, sustainable development encourages economic growth. However, it not only focuses on increasing quantity, but also on improvement of quality.

Sustainable development is an approach to development that is based on protecting the natural environment, improving and enhancing the quality of life, and coordinating the carrying capacity of environmental resources.

There are many current international and domestic studies on the problem of how to quantize sustainable development, which faces many challenges. We selected a quantitative indicator (DD) for the sustainability of socio-economy and water environment. Its basic concept is based on an approach to the measurement of current sustainable development, such as the social welfare function method and the index system method, through quantitative description of fuzzy mathematics to combine the integrate DD indexes of two duplet sets. DD represents the integration of the index LI describing the water environment and relative eco-system quality with socio-economic development indicator EG described by the GDP function. DD is a quantized measure of sustainable development within the $\mathrm{T}$ time frame in the water resource system (dimensionless quantity), where $D D(\mathrm{~T}) \in[0,1]$. It can be expressed as (Xia et al., 2014):

$$
D D(\mathrm{~T})=E G(\mathrm{~T})^{\beta_{1}} \times L I(\mathrm{~T})^{\beta_{2}}
$$

where $L I$ is the water environment and relative eco-system quality, $E G$ is socio-economic development as description of "economic growth", $\beta_{1}$ and $\beta_{2}$ are exponential weights given to the quantized value of "economic growth" and the membership of "bearable", respectively. Values of $\beta_{1}$ and $\beta_{2}$ are assigned according to the degree of importance.

$D D(T)$ is a "scale" of "development" for the T phase. For the same system and phase, the larger the value of $D D(T)$, the higher the degree of development will be and the higher the 
benefits. Among them, "sustainability" can be defined as $D D(T) \geqslant D D(T-1)$. Thus, it can seek the optimal development approach through adjusting the internal structure and resource allocation, etc.

(a) Actually, "bearable" membership $L I(T)$ is a quantitative description of human existence in the environment. It can describe the "bearable" degree through membership in fuzzy mathematics. It assumes an indicator $\mathrm{Yi}(T)$ (where $i$ is the index number and $T$ is time phase) and selects the limit Yi0. The corresponding membership is $\mu \operatorname{LI}(Y i(T))$. The bearable membership of the whole system is:

$$
L I(T)=\prod_{i=1}^{n_{1}} \mu_{L I}^{a i}(Y i(T))
$$

where $n_{1}$ indicator considers whether or not the whole system is bearable, $\operatorname{LI}(T)$ refers to bearable membership of the whole system at the $T$ phase, and $a i$ refers to the index weight of the $i$ th indicator. A value for $a i$ is assigned according to the degree of importance of each indicator.

(b) "Economic growth", $E G(T)$, is a quantitative description of economic growth. $S P(T)$ is the economic index (such as gross national product, gross output values of industry and agriculture, national income, per capita gross national product). The value of $S P(T)$ for the initial year (the "basic unit" for the time quantum is set as a year) is set as the reference value $S P_{0}$. To realize the nondimensionalization of the data, initialization can be performed as $x=$ $S P(\mathrm{~T}) / S P_{0}$. Actually, $x$ is the economic growth ratio of any year relative to the initial year. The "economic growth index" is quantified as

$$
E G(T)=\frac{x-a}{x+a}
$$

where $a$ is the undetermined coefficient and $x=S P(T) / S P_{0}$.

\subsection{Analysis of regulation variables for reducing water resource vulnerability under climate change}

Decision variables for water resource adaptive management under the background of climate change refer to the applicable countermeasures in terms of human activities in response to climate change. Scholars at home and abroad, such as Xia Jun et al., proposed an evaluation model and method for assessing water resource vulnerability (Xia et al., 2012; Chen, 2014). The indicator system for water resource vulnerability includes three key indicators: water-use driven mobilization level (r: use-to-availability as a percentage of water availability), water resource carrying capacity (P/Q: population per water unit), and per capita water use $\left(\mathrm{W}_{\mathrm{D}} / \mathrm{P}\right.$ : water intake in cubic meters per capita per year). The three indicators are closely related to the maximum available water resource $\left(\mathrm{WD}_{\max }\right)$, total water consumption (WD), eco-water use (WE), minimum eco-water demand ( $\mathrm{WE}_{\min }$ ), water use efficiency (WUE) and criterion compliance rate of the water function area (RWF), as well as other based indexes. The regulation variables can be further determined according to the internal relationship (Figure 2) between key indicators and the adaptability to combat climate change and the reduction of water resource vulnerability. These variables include the water resource multi-objective decision variables: total water consumption $\left(\mathrm{x}_{1}\right)$, water use efficiency $\left(\mathrm{x}_{2}\right)$, criterion compliance rate of the water function area $\left(\mathrm{x}_{3}\right)$, and eco-water demand $\left(\mathrm{x}_{4}\right)$. 


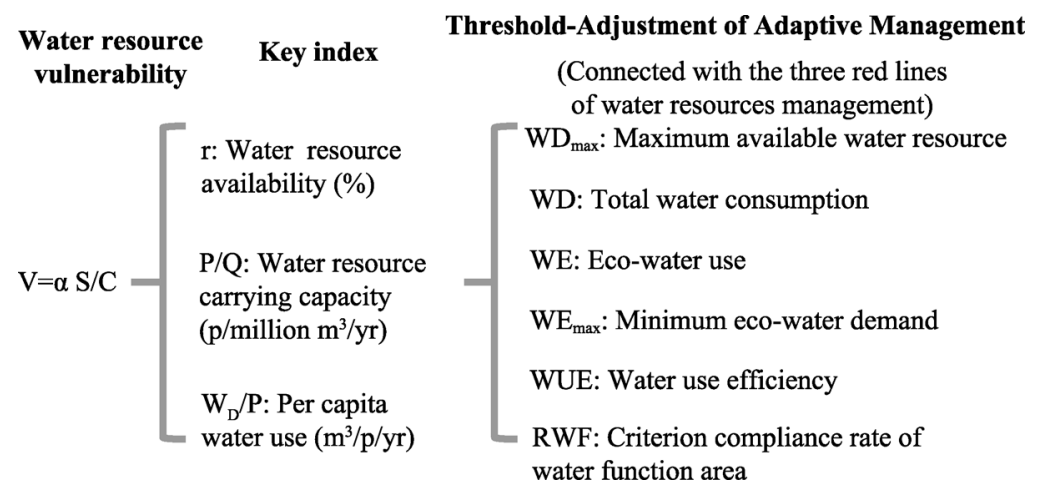

Figure 2 Key index of water resource vulnerability and adaptation

\subsection{Multi-objective decision making model of adaptive water management under climate change}

Specific to regulation principles and the relationship between the vulnerability and adaptation of regulation variables, the water quality of the water balance constraints is connected by the watershed hydrology model of the water resource system. Through extraction, the multi-objective optimization model of water resource adaptation can be built to combat climate change. The general structure of the objective function of the model is shown below:

$$
\max F(\mathrm{X})=\max \left\{f_{1}(\mathrm{X}), f_{2}(\mathrm{X}) \cdots f_{\mathrm{n}}(\mathrm{X})\right\} \text {, s.t. } X \in S, X \geqslant 0
$$

According to the physical status of the Eastern China Monsoon Region and the representative basin, we selected the following two key indicators as the multi-objective function.

1) Decrease the target of vulnerability:

The minimum water resource vulnerability (V) of each planned year of the region represents the maximum. Namely:

$$
\min \left(f_{2}(X)\right)=\min \left(\sum_{T=1}^{N} V(T) / N\right)
$$

At the solution of the objective function optimization, it is necessary to transform the subgoal $f_{2}(X)$ to the maximum total goal, namely:

$$
\max \left(f_{2}(\mathrm{X})\right)=\max \left(\frac{1}{\sum_{T-1}^{N} V(T) / N}\right)
$$

subject to the constraint condition:

$$
\left.\begin{array}{l}
L I(T) \geqslant L I_{0} \\
V(\mathrm{~T}) \leqslant V(\mathrm{~T})_{0} \\
S D D T \geqslant S D D T_{0} \\
W U_{m} \leqslant\left(W U_{m}\right)_{\max } \\
W U E_{m, \min } \leqslant W U E_{m} \leqslant 1 \\
\left(Q E_{m, i}\right)_{\min } \leqslant Q E_{m, i}
\end{array}\right\}
$$


where $S D D T$ is the membership degree of the trend, $W U_{m}$ is the available water of the meterage unit, $W U E_{m}$ is the water resources utilization rate of the meterage unit; $\left(Q E_{m, i}\right)_{\min }$ is minimum demand discharge of the NO.m river basin, and $Q E_{m, i}$ is the actual discharge of the NO.m river basin.

2) Targets of the sustainability of socio-economy and water environment:

The sustainability of socio-economy and water environment (DD) of each planned year of the region represents the maximum. Namely,

$$
\max \left(f_{1}(X)\right)=\max \left(\sum_{T=1}^{N} D D(T) / N\right)
$$

where $D D$ is the quantized value (dimensionless quantity) of the sustainability of socio-economy and water environment within the time frame $T$, where $D D(T) \in[0,1]$.

\subsection{Multi-objective model solution}

The multi-objective model solution is a complicated nonlinear and dynamic planning problem. Because the water resources system under the climate change is a large-scale system, the multivariable solution is a typical high dimension problem. To solve the problem, the paper proposed a solving method to convert the multi-object to a single-object. According to the water resource vulnerability $(\mathrm{V})$, the logical relationship between the sustainability of socio-economy and water environment (DD) and adaptive management can further simplify the multi-object to a single-object to establish a quantitative method for an integrated measure function called VDD. The core is economic growth that simultaneously considers damage to the environment, namely, comprehensive benefit analysis of economic growth, environmental loss, and water resources vulnerability. In addition, it studies the functional relationship and analyzes the comprehensive benefits of water resource regulation.

Under the impact of climate change, the larger the water resource vulnerability, the weaker the water resources will be; the higher the sustainable development, the stronger the

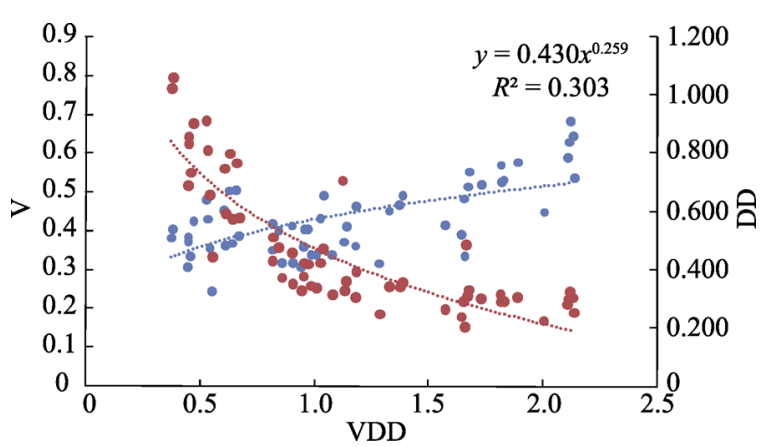

Figure 3 Tendency correlation analysis of VDD, V and DD adaptive capacity of the water resource will be. It can be seen from the correlation analysis in Figure 3 that the adaptive management object of a water resource is in direct proportion to its sustainable development, and it is inversely proportional to water resource vulnerability. This means that the adaptability of water resources management goals and sustainable development may reach a high level.

Consequently, the relationship between sub-objective functions can combine and simplify the multi-objective functional model of water resource adaptive management to the following single objective function:

$$
V D D(\mathrm{~T})=\frac{1}{V(\mathrm{~T})} \cdot D D(\mathrm{~T})=\frac{E G(\mathrm{~T})^{\beta_{1}} \cdot L I(\mathrm{~T})^{\beta_{2}}}{V(\mathrm{~T})}
$$


The goal of adaptive management is to select the adjustment measure for comprehensive benefit maximization. The objective function is as below:

$$
\max (\mathrm{BTI})=\max \left(\sum_{T=1}^{N} V D D(T) / N\right)
$$

Because the conversion is for a single objective function, each regulation variable has a direct relationship with the target. Satisfactory solutions can be obtained through a physical feasible design domain to detect the optimal solution. The solution method is also simple and effective.

\section{Application of adaptive water resources planning and management}

\subsection{Analysis of the status quo of water resources in the Eastern China Monsoon Region}

The approach above has been applied to adaptive water resources planning and management for case study of China with new policy, called as the strict management of water resources based on the three red line controls, i.e., the control of total water use by the total water resources allocation, the control of lower water use efficiency by the water demand management and control of the total waste water load by water quality management in the study region that covers major eight big river basins including Yangtze River, Yellow River, Haihe River, Huaihe River. This region, which is a back inland plateau and facing the sea, has about $45 \%$ of the country land area and $95 \%$ of the country's total population. The vulnerability of water resources here has a significant spatial anisotropy.

Under current conditions (2000), the calculation results and space distribution of water resource vulnerability and sustainable development in the Eastern China's Monsoon Region are shown in Figures 4 and 5. The calculation results and the spatial pattern of the integrated development bene-

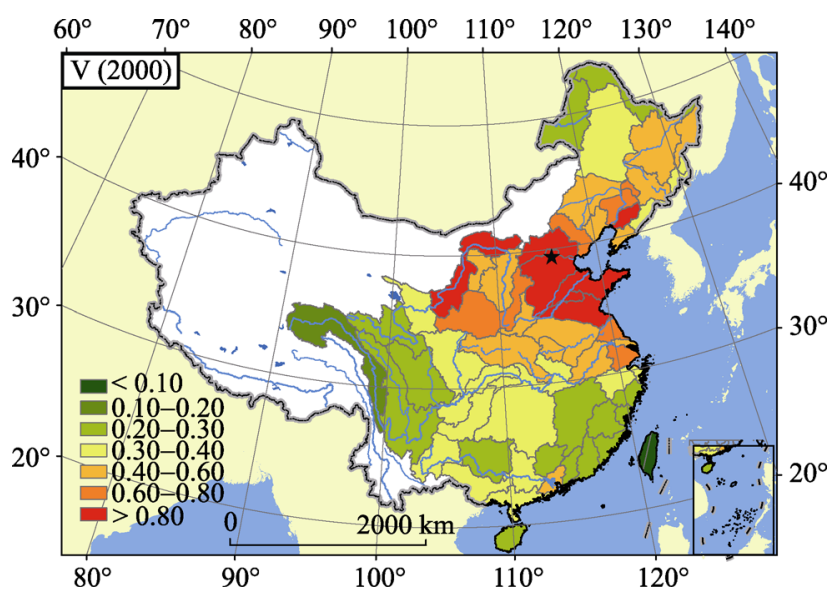

Figure 4 V: water resource vulnerability (2000)

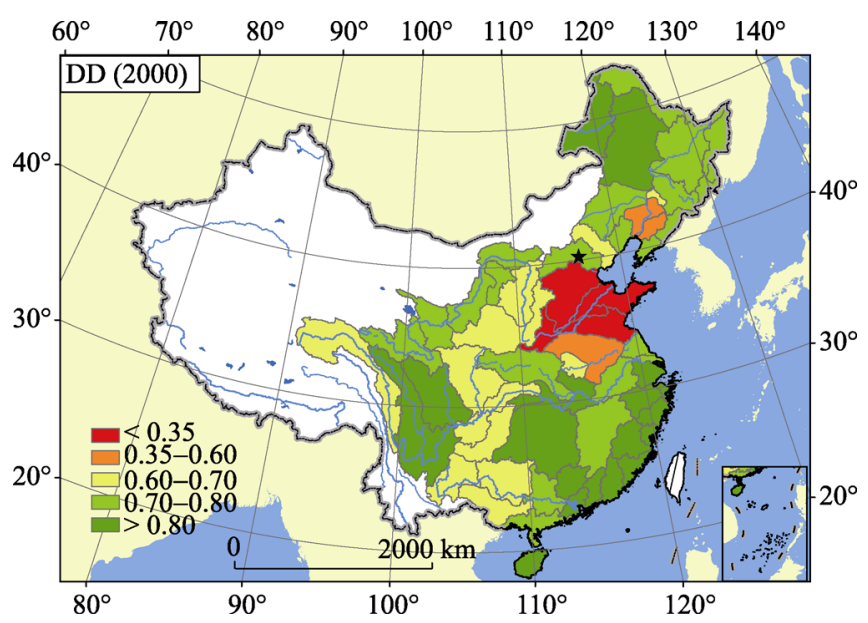

Figure 5 DD: degree of sustainable development (2000) 


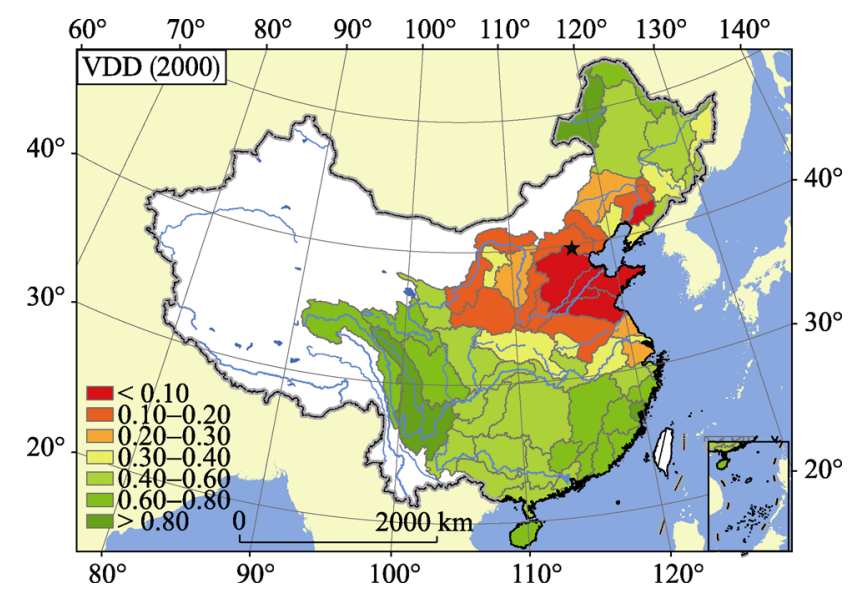

Figure 6 VDD: development and comprehensive benefits (2000) fit objective function are shown in Figure 6 . The following indicators are adopted to calculate VDD, considering the main indicators of national water conservancy development and the actual application data (Statistic Bulletin on China Water Activities et al., 2000-2011) such as Statistic Bulletin on China Water Activities. Among them, the economic performance index (EG) includes per capita GDP bearable indicators (LI), including the river length ratios of the five types of water.

The analysis and evaluation indicate that, under the status quo, the coastal economic zones, the Beijing-Tianjin-Hebei region (with Beijing as the center), and the northeast part have rapid socio-economic development in China, in addition to drainage basins with severe water pollution in the Haihe River basin of North China. All of these regions have water resources vulnerability. Taking the Haihe River basin as an example, because the economic conditions are developed in association with serious environmental deterioration, the sustainable development (DD) is at a minimum. Simultaneously, the water resource vulnerability $(\mathrm{V})$ is at a maximum. Thus, the VDD value of the water resource adaptation to environmental deterioration is the worst. It can be seen from the analysis that the comprehensive characterization results of water resource vulnerability and sustainable development are effective and reasonable.

From Figure 6, it can be seen that the regions with the worst integrated development effectiveness in the Eastern China Monsoon Region, where the values of VDD are lower than 0.2 , are mainly located in the Haihe River basin. The Haihe River basin is followed by the Yellow River and Huaihe River basins, where the VDD values are between 0.2 and 0.4 . Most of the other regions, such as the Yangtze River basin, have moderate integrated development effectiveness, where the VDD value is between 0.4 and 0.6. The VDD value at the westernmost part of the Yangtze River basin is the highest, indicating the best integrated development effectiveness. From the above analysis, adaptive management measures are urgently required for improving the integrated development effectiveness of the water resources of the river basins.

\subsection{Adaptation control analysis for secondary drainage basins of the Eastern China Monsoon Region based on national policy under future climate conditions}

Because the impact of climate changes on the water resources in the future has not been determined, it is appropriate to use the most adverse scenario analysis in terms of climate change based on the principle of "the minimum regret". It is an efficient approach to risk analysis of the nondeterminacy of climatic variation. The future climate change scenarios include the Representative Concentration Pathways emission scenarios RCP2.6 (low), 
RCP4.5 (moderate) and RCP8.5 (high). This research adopted RCP4.5, which is close to the emission situation of 2030 in the future. Analyses of various possible impacts on inflow and water consumption are carried out, and the unfavorable scenario (minimum runoff) of climate change in 2030 is selected for the analysis of different adaptive countermeasures and measures based on VDD. The corresponding VDD results of the unfavorable scenario of climate

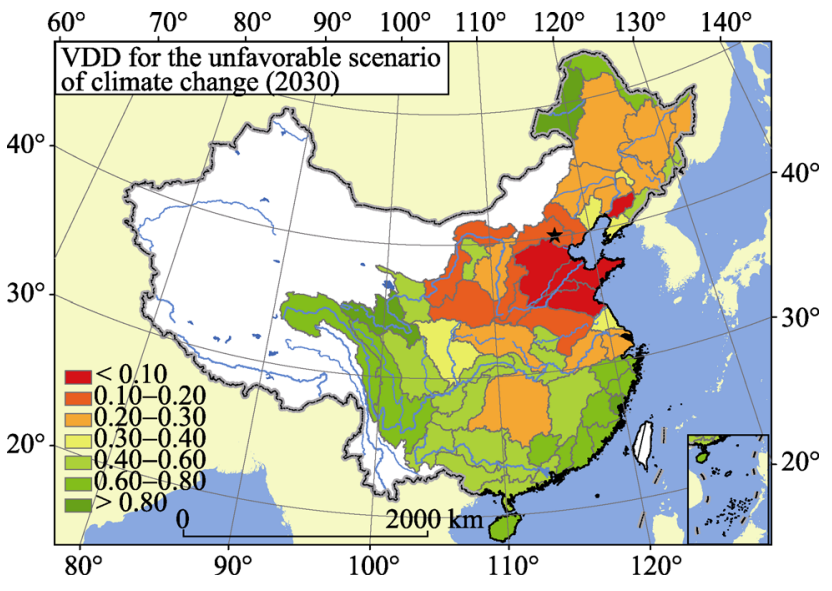

Figure 7 VDD for the unfavorable scenario of climate change in 2030 change in 2030 are shown in Figure 7.

The VDD value of each drainage basin has decreased in terms of the worst situation compared with that of the year 2000, namely, the integrated development effectiveness has become worse. This indicates that the sustainable development tendency of the water resource encounters a critical challenge.

The following adaptive control measures will be adopted for the unfavorable scenario of climate change in 2030 according to sustainable development and for the strict management of water resources: (1) regulation of the total water consumption of 700 billion $^{3}$ and revision of the decomposed total quantity control in the each river basin of Eastern China Monsoon Region; (2) water use efficiency regulation (agriculture, industry, life), where the water use efficiency in 2030 will reach the world "advanced" level, the industrial added value per every ten thousand RMB will decrease below $40 \mathrm{~m}^{3}$, and the efficient utilization coefficient of irrigation water will be above 0.6; (3) water quality management regulation to determine the threshold for allowable limits for dirty accommodation in the water functional area, where the main control of the total quantities of the main contaminants should be within the water functional area until 2030 and the criterion compliance rate of water function area will be up to $95 \%$; (4) eco-water regulation for rivers and lakes, where the minimum eco-water demand of the water resource plan will gradually improve the assurance rate of eco-water utilization before 2030 .

To seek the path of adaptive water management in the Eastern China Monsoon Region, we need to analyze the effect of different management strategies and the optimal countermeasure proposal. The combination of regulatory decisions is shown in Table 1.

According to the target (i.e., theories and methods of adaptive water management under climate change), we completed the adaptive management analysis of the 15 different scenarios, which focused on those of schemes 1, 2, 3, 4, and 15 .

Results of the analyses of $\mathrm{V}$ and DD after each single control and the integrated control are shown in Figures 8 and 9 . Results of the analyses of $\Delta \mathrm{V}(\%)$ and $\Delta \mathrm{DD}(\%)$ after controlling countermeasures are shown in Figures 10 and 11.

The spatial distribution of the VDD results for secondary drainage basins of the Eastern China Monsoon Region after each single control and the integrated control are shown in Figures 12-16. 
Table 1 Combination of regulatory decisions

\begin{tabular}{|c|c|c|c|c|}
\hline \multirow{2}{*}{ Scheme } & \multicolumn{4}{|c|}{ Control variables (Decision variables) } \\
\hline & Water consumption & Water use efficiency & Criterion compliance rate & Eco-water \\
\hline 1 & $\bullet$ & & & \\
\hline 2 & & $\bullet$ & & \\
\hline 3 & & & $\bullet$ & \\
\hline 4 & & & & 0 \\
\hline 5 & $\bullet$ & ○ & & \\
\hline 6 & ○ & & $\bullet$ & \\
\hline 7 & ○ & & & $\bullet$ \\
\hline 8 & & - & ○ & \\
\hline 9 & & $\bullet$ & & • \\
\hline 10 & & & • & • \\
\hline 11 & $\bullet$ & - & $\bullet$ & \\
\hline 12 & $\bullet$ & $\bullet$ & & $\bullet$ \\
\hline 13 & & • & $\bullet$ & $\bullet$ \\
\hline 14 & $\bullet$ & & $\bullet$ & $\bullet$ \\
\hline 15 & $\bullet$ & ○ & $\bullet$ & ○ \\
\hline
\end{tabular}

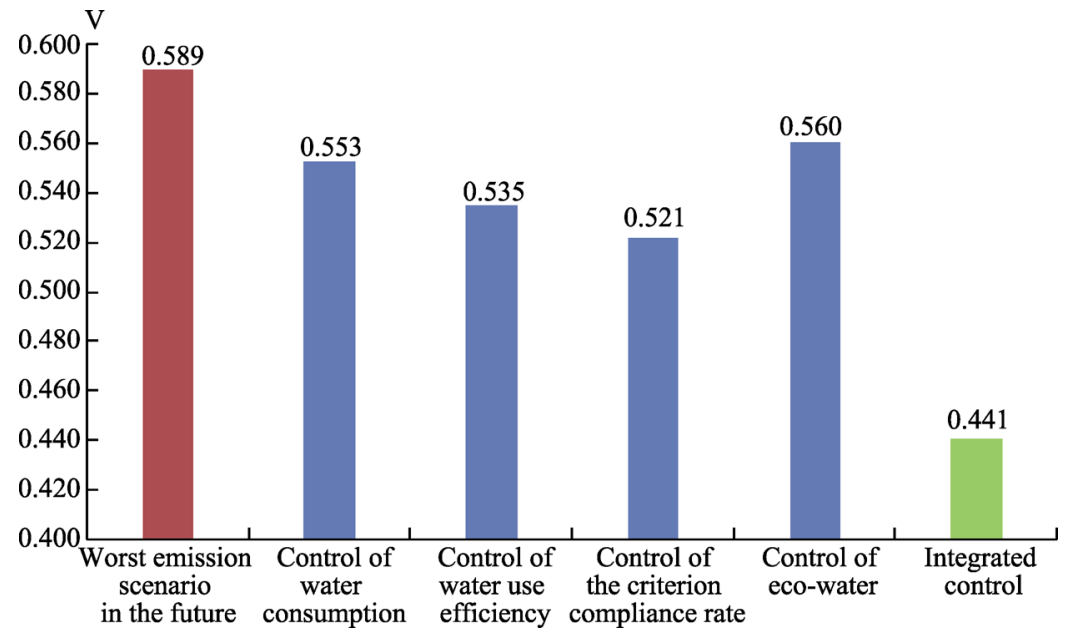

Figure 8 Result analysis of $\mathrm{V}$ after control

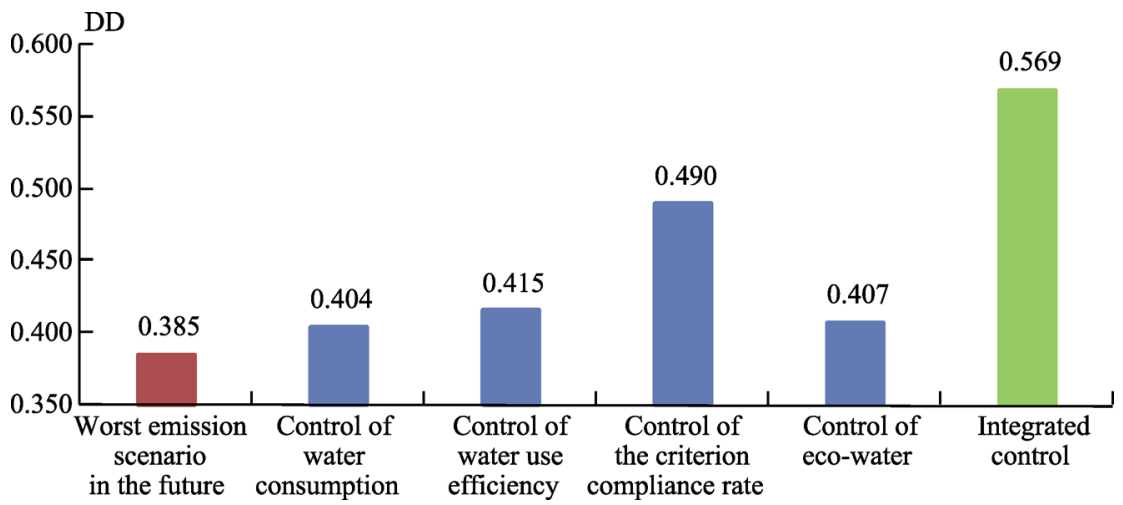

Figure 9 Result analysis of DD after control 


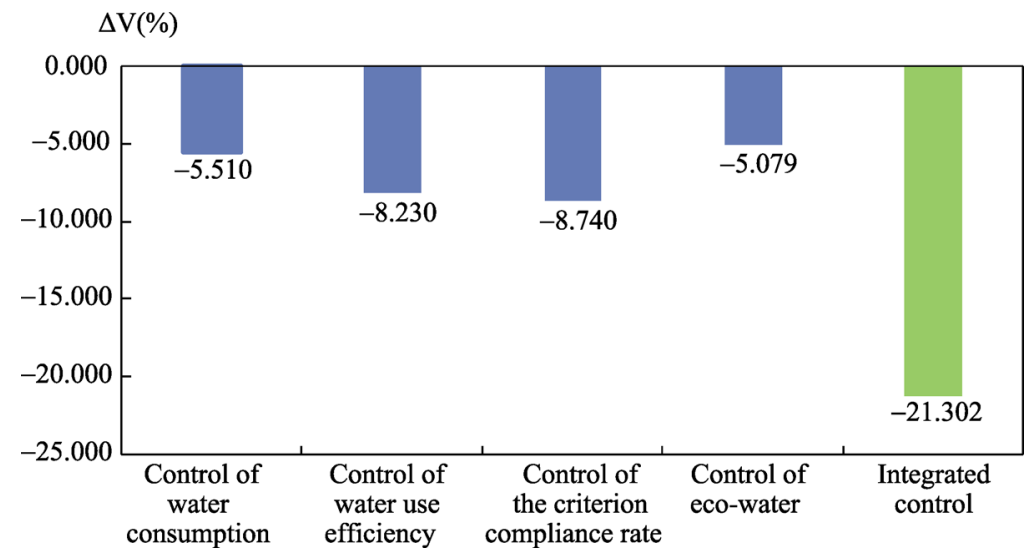

Figure 10 Result analysis of V (\%) after control

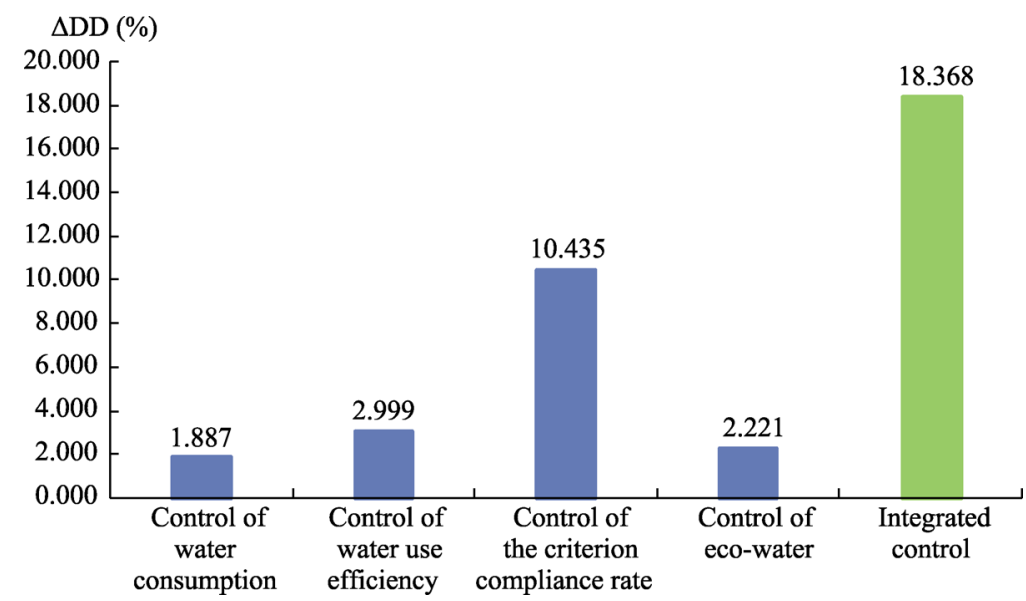

Figure 11 Result analysis of $\Delta \mathrm{DD}(\%)$ after control

According to the above analysis, it can be seen that the effect after different control schemes is different for the unfavorable scenario of climate change in 2030 in the eight river basins of the Eastern China Monsoon Region. For the goal of reducing water vulnerability, the most sensitive single controls include water use efficiency and the criterion compliance rate control, followed by water consumption and eco-water control. For the goal of sustainable management of water

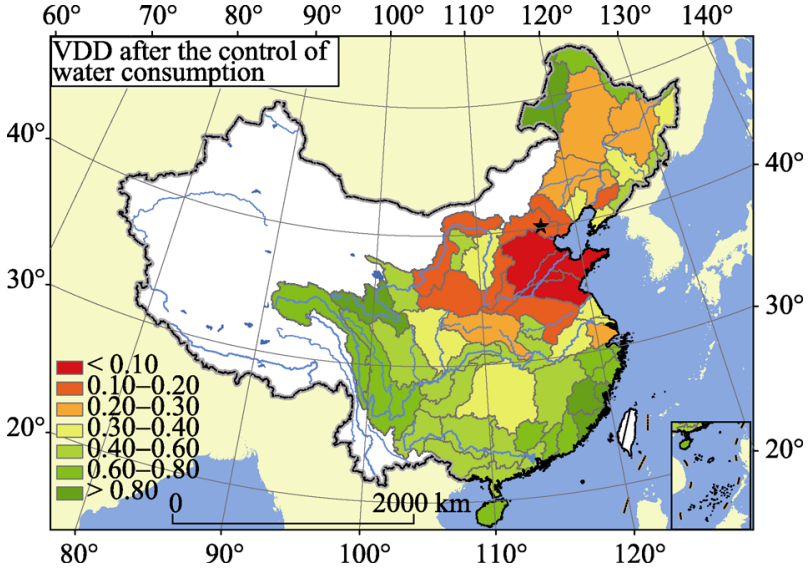

Figure 12 VDD after the control of water consumption (scheme 1) resources, the most sensitive single controls are the criterion compliance rate control, followed by water use efficiency, eco-water control and water consumption. In the satisfactory 
set for the targets of $\mathrm{V}$ and $\mathrm{DD}$, scheme 15 is optimal, as it results in a $21.3 \%$ decrease in $\mathrm{V}$ and an $18.4 \%$ increase in DD. Different from previous studies, this paper provides a method to quantify the change of the vulnerability and sustainable development for each river basin after different measures are taken. For example, after taking comprehensive control measures (scheme 15), $\mathrm{V}$ of the Haihe River basin has a reduction of $33.1 \%$, while $\mathrm{V}$ of the Huaihe River basin decreased by $25.4 \%$, and $\mathrm{V}$ of the Yellow River Basin decreased by $16.6 \%$; also DD of the Haihe River basin increased as high as $18.69 \%$, while DD of the Huaihe River Basin increased by $15.6 \%$, and DD of the Yellow River basin increased by $10.4 \%$.

It can be seen from the spatial distribution of results that VDD values in certain regions will be improved to varying degrees. The influences of different measures are different for different drainage basins: after regulation of the total water consumption, VDD at the middle of the Songhua and Yangtze River basins attained an average value. The integrated development effectiveness will be raised to a higher level. After regulation of ET, the integrated development effectiveness in the eastern Yellow River basin and northwestward in the Liaohe River basin will be promoted to a higher level. After regulation of the criterion compliance rate of the water function area, the VDD value will vary for a small number of areas in the

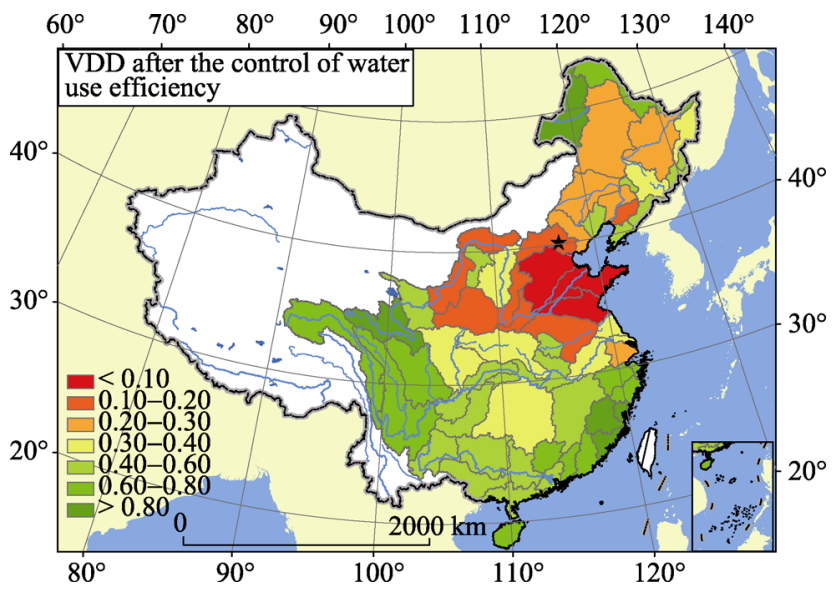

Figure 13 VDD after the control of water use efficiency (scheme 2)

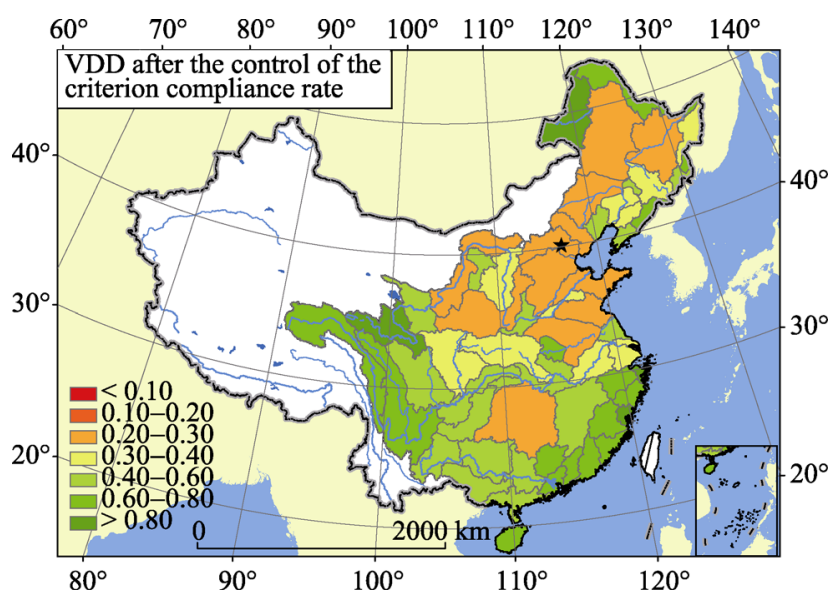

Figure 14 VDD after the control of the criterion compliance rate (scheme 3)

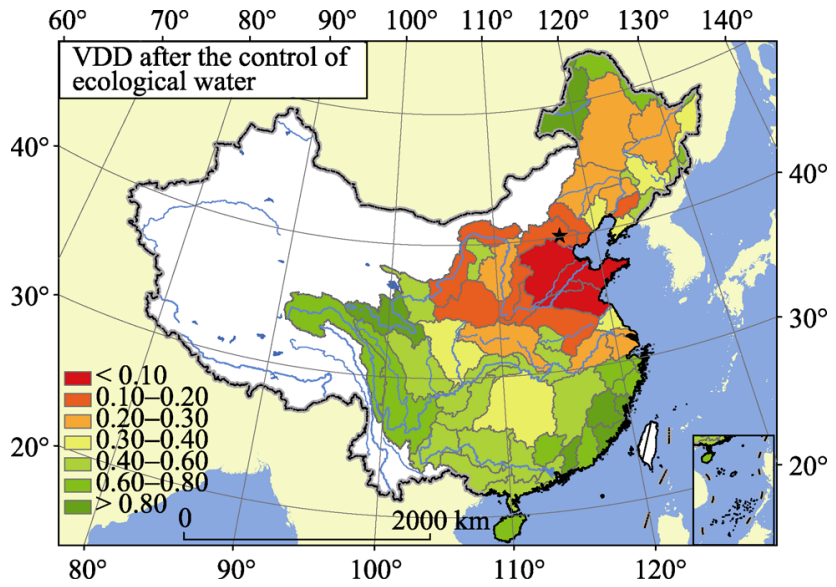

Figure 15 VDD after the control of eco-water (scheme 4) 
Yellow River, Haihe River and Liaohe River basins. The VDD values will increase to various degrees after regulation of eco-water utilization in certain drainage basins. From that, it can be seen that the VDD values will determine the influence of different control measures on the degree of benefit to the integrated development of the river basin, and it will choose the most targeted measure as the most effective adaptive control measure.

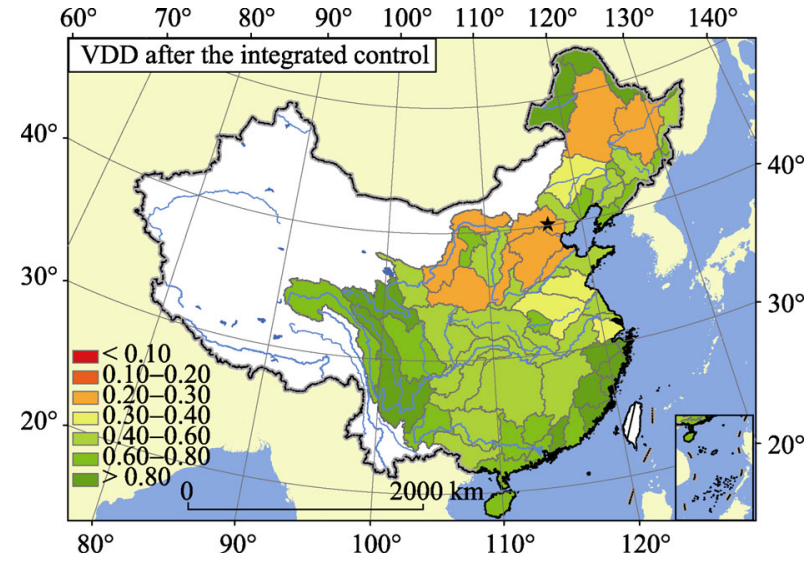

Figure 16 VDD after the integrated control (scheme 15)

\section{Conclusions}

1) The paper focuses on studies of the transformation of multi-objects to single-objects based on interactive cooperation between water resource vulnerability and adaptive management. It proposed a comprehensive development benefit function (VDD) for coupling "development indicator measurement" (DD) and "water resource vulnerability" (V). In addition, it verified the feasibility and rationality of expressing the VDD function through examples. Eventually, it proposed a theoretical basis for specific adaptive management measures.

2) The calculation results and space distribution analysis of VDD in the Eastern China Monsoon Region showed that the influence of climate change on water resources is significant in this region. Thus, it is urgently required to take adaptive management measures to improve the integrated development effectiveness of the water resources of the river basins.

3) Based on the integrated measure function VDD, this approach has been applied to adaptive water resources planning and management for case study of China with new policy, called as the strict management of water resources based on the three red line controls, i.e., the control of total water use by the total water resources allocation, the control of lower water use efficiency by the water demand management and the control of the total waste water load by water quality management in the Eastern China Monsoon Region. The results showed that the effects in certain regions are more appreciable than in others and that relatively sensitive control variables can be recognized. Adjustment measures can be specifically proposed. It turned out that the single control effect of the criterion compliance rate and water use efficiency are more obvious, and the integrated control of the four measures gains the most significant effect, which can cause a significant increase in the comprehensive benefits of sustainable development. The single control effect can enhance the sustainable development of comprehensive benefits, and it can alleviate the water resources vulnerability under climate change mitigation within the maximum range. And for the unfavorable scenario of climate change in 2030, adaptive management effect of the criterion compliance rate and water use efficiency is most appreciable through new water policy of the three red line controls, which can reduce $21.3 \%$ of the water resources vulnerability (V) and increase $18.4 \%$ of the sustainability of socio-economy and water environment (DD). 


\section{Acknowledgements}

The authors appreciate the National Climate Centre for simulation results of climate changes by utilizing a regional climate model. The authors also appreciate the China Renewable Energy Engineering Institute for their predictions of water-demand.

Other data sources include the China Water Conservancy Almanac, the National Water Conservancy Development Statistical Bulletin, the China Water Resources Bulletin, the China Floods and Droughts Bulletin and the China City Statistical Yearbook.

\section{References}

Akamani K, Wilson P I, 2011. Toward the adaptive governance of transboundary water resources. Conservation Letters, 4(6): 409-416.

Allan C, Curtis A, Stankey G et al., 2008. Adaptive Management and Watersheds: A Social Science Perspective. Jawra Journal of the American Water Resources Association, 44(1): 166-174.

Aronson J, Kigel J, Shmida A et al., 1992. Adaptive phenology of desert and mediterranean populations of annual plants grown with and without water-stress. Oecologia, 89(1): 17-26.

Bates B, Kundzewicz Z W, Wu S et al., 2008. Climate change and water. Intergovernmental Panel on Climate Change (IPCC): IPCC Technical Paper VI.

Bulletin of Flood and Drought Disasters in China, 2000-2011. Beijing: China Water \& Power Press. (in Chinese)

Chen Junxu, 2014. Research on vulnerability of water resources and adaption management to improve water quality of the water function area under changing environment in eastern monsoon areas [D]. Beijing: University of Chinese Academy of Sciences. (in Chinese)

Chen J, Xia J, Zhao Z et al., 2016. Using the RESC model and diversity indexes to assess the cross-scale water resource vulnerability and spatial heterogeneity in the Huai River Basin, China. Water, 8(10): 431. doi: 10.3390/w8100431.

China City Statistical Yearbook, 2000-2011. Beijing: China Statistical Press. (in Chinese)

China Water Conservancy Yearbook, 2000-2011. Beijing: China Water \& Power Press. (in Chinese)

China Water Resources Bulletin, 2000-2011. Beijing: China Water \& Power Press. (in Chinese)

Govert D Geldof, 1995. Adaptive water management: Integrated water management on the edge of chaos. Water Science and Technology, 32(1): 7-13.

Gregory R, Failing L, Higgins P, 2006. Adaptive management and environmental decision making: A case study application to water use planning. Ecological Economics, 58(2): 434-447. PubMed PMID: WOS: 000238671700015 .

Holling C S, 1978. Adaptive Environmental Assessment and Management. London: John Wiley \& Sons.

IPCC, 2013. Climate Change 2013: The Physical Science Basis. Work Group I Contribution to the IPCC Fifth Assessment Report (AR5). Stockholm, Sweden: IPCC.

Jin Shuai, Sheng Zhaohan, Liu Xiaofeng, 2010. Complexity analysis on watershed system and adaptive management. China Population, Resources and Environment, 20(7): 60-67. (in Chinese)

Liao Wengen, Shi Qiuchi, Beng Jing, 2004. Advanced research about water ecology and water environment subject and the development trends. China Water Resources, 22: 34-36. (in Chinese)

Liu Fang, 2010. Water Resources Adaptive Management based on AHP. Modern Management Science, (9): 108-110. (in Chinese)

Moglia M, Cook S, Sharma A K et al., 2011. Assessing decentralised water solutions: Towards a framework for adaptive learning. Water Resources Management, 25(1): 217-238.

Pahl-Wostl C, 2008. Requirements for Adaptive Water Management. Berlin: Springer-Verlag.

Pahl-Wostl C, Downing T, Kabat P et al., 2005. Transition to Adaptive Water Management: The NeWater Project. NeWater Report Series, No. 1.

Sophocleous M, 2000. From safe yield to sustainable development of water resources: The Kansas experience. Journal of Hydrology, 235(1): 27-43.

Statistic Bulletin on China Water Activities, 2000-2011. Beijing: China Water \& Power Press. (in Chinese)

Tong Jinping, Wang Huimin, 2006. Research on water resources adaptive management in river basin. Soft Science, 20(2): 59-61. (in Chinese)

Xia Jun, Liu Chunzhen, Ren Guoyu, 2011. Opportunity and challenge of the climate change impact on the water resource of China. Advances in Earth Science, 26(1): 457-464. (in Chinese)

Xia Jun, Qiu Bing, Li Yuanyuan, 2012. Water resources vulnerability and adaptive management in the Huang, Huai and Hai river basins of China. Water International, 37(5): 523-536.

Xia Jun, Thomas Tanner, Ren Guoyu et al., 2008. Potential impacts of climate change on water resources in China: Screening for adaptation and management. Advances in Climate Change Research, (4): 215-219. (in Chinese)

Xia Jun, Zuo Qiting, Shao Mincheng, 2003. Sustainable Utilization of Water Resources in Bosten Lake: Theory, Method and Practice. Beijing: Science Press. (in Chinese) 